\title{
CORRELAÇÃO ENTRE CRITÉRIOS CLÍNICOS E CRITÉRIOS LABORATORIAIS NO DIAGNÓSTICO DE VAGINOSE BACTERIANA
}

\author{
ELIANA CAROLINA VESPERO 1 \\ ELBENS MARCOS MINORELLI DE AZEVEDO² \\ MARSILENI PELISSON ${ }^{3}$ \\ MÁRCIA REGINA ECHES PERUGINI ${ }^{3}$
}

\begin{abstract}
VESPERO, E. C.; AZEVEDO, E. M. M.; PELISSON, M.; PERUGINI, M. R. E. Correlação entre critérios clinicos e critérios laboratoriais no diagnóstico de vaginose bacteriana. Semina: Ci. Biol. Saúde, Londrina, v. 20/21, n. 2, p. 57-66, jun. 1999/2000.
\end{abstract}

\begin{abstract}
RESUMO: Vaginose bacteriana pode ser definida por variáveis clínicas e microbiológicas. Os critérios de Amsel permite o diagnóstico de vaginose bacteriana quando 3 dos 4 critérios são detectados: 1) pH vaginal $>4,5$; 2) teste positivo de aminas com $\mathrm{KOH} 10 \%$; 3) presença de células alvo; 4) presença de corrimento vaginal branco, fino e homogêneo. Este trabalho teve como objetivo comparar a eficácia dos critérios de Amsel e gradiente de Nugent no diagnóstico de vaginose bacteriana. Foram avaliadas 100 amostras de pacientes com sinais e sintomas clínicos de afecção vaginal, no período de setembro de 1999 a outubro de 2000, no setor de Ginecologia e Obstetrícia do Ambulatório do Hospital de Clínicas. As pacientes foram submetidas a exame ginecológico a fim de verificar o aspecto da mucosa e conteúdo vaginal . Coletou-se amostras para medir o $\mathrm{pH}$ vaginal, realizar o teste das aminas, exame a fresco e bacterioscopia ao Gram. Foi determinado o gradiente de Nugent e comparado aos critérios de Amsel para caracterização de vaginose bacteriana. Incidência de vaginose bacteriana na população estudada foi de $34 \%$ para os critérios laboratoriais e $14 \%$ para os critérios clínicos. Não houve concordância significativa (Kappa=0,47) entre os critérios de Amsel e gradiente de Nugent. O que leva a colocar em discussão as rotinas médicas ginecológicas que caracteriza a vaginose bacteriana somente através de sinais clínicos.
\end{abstract}

PALAVRAS-CHAVE: Vaginose bacteriana; critério clínico; critério laboratorial.

\section{INTRODUÇÃO}

As afeções cérvico-vaginais apresentam relevante importância médico-social, não só conseqüente à sintomatologia desconfortável, como também por contribuir para a disseminação das Doenças Sexualmente Transmissiveis (DST). Tais infecções podem estar associadas a um aumento de risco de complicações durante o ciclo gravídicopuerperal tais como: parto prematuro, ruptura prematura de membranas, corioaminiotites, endometrite, sepsis pós parto e infecções pós operatórias, além de contribuir na gênese da neoplasia intra epitelial cervical (Hill \& Livengood, 1994; Haas et al., 1999).

Alguns clínicos sugerem que a maioria das pacientes portadoras de vulvovaginites podem se beneficiar através de tratamento baseado no diagnóstico clínico. Entretanto, a multiplicidade de quadros atribuidas a um mesmo agente ou a freqüência de processos semelhantes, causadas por vários agentes, torna difícil o diagnóstico baseado apenas em dados clinicos. Dessa maneira, deve-se evitar a terapia empírica, pois o tratamento inadequado além de induzir a infecções recorrentes e ser oneroso, não contempla o estado de transmissor. (Barnes, 1989; Spiegel, 1991; Thomason et al., 1991).

A área genital feminina tem uma microbiota bastante dinâmica e complexa, apresentando um equilibrio definido. A flora endógena lactobacilar comensal e o $\mathrm{pH}$ vaginal, podem variar na dependência da época do ciclo menstrual e do uso de fármacos antibióticos, quimioterápicos hormonais e anti-inflamatórios. Fatores endógenos e exógenos, como idade da paciente e fundo hormonal, também são capazes de afetar a composição desta microbiota (Fonseca et al., 1997; Cauci et al., 1998; Lucena et al., 1999).

\footnotetext{
${ }^{1}$ Aluna do curso de especialização em Análises Clínicas-UEL

2 Professor-adjunto do setor de Ginecologia e Obstetrícia do Departamento Materno Infantil e Saúde Coletiva do Centro de Ciências da Saúde - UEL.

${ }^{3}$ Professora-adjunta da disciplina de Microbiologia Clínica do Departamento de Patologia Aplicada, Legislação e Deontologia do Centro de Ciências as Saúde - UEL.
} 
Vaginose bacteriana(V.B.) foi primeiramente relatada em 1955 por Gardner e Dukes, que descreveram os sinais clínicos, sintomas e a natureza distintiva do conteúdo vaginal associados a V.B.. Enquanto a complexidade do quadro microbiológico foi bem descrito, a etiologia e a patogênese da condição permanecem mal compreendidos, e as razões sobre o porque a flora de lactobacilos saudáveis é substituida por um coquetel opressivo de bactérias ainda não foi bem elucidado (Priestley et al. 1997).

Vaginose bacteriana é caracterizada pela mudança do predomínio da flora de lactobacilos para vários patógenos associados com síndromes genitais como: Gardnerella vaginalis, Mobiluncus spp., Porphyromonas spp., Prevotella spp., Pepstreptococcus spp. (Sobel, 1997; Macseen \& Ridgway, 1998).

Tem sido notável, nas últimas décadas, um aumento das vaginoses bacterianas como causa de corrimento vaginal. Ocorrências que variam de 10 a $41 \%$ na populaçăo em geral, em torno de $50 \%$ a $60 \%$ em mulheres com D.S.T. e de 6 a $32 \%$ em mulheres grávidas, têm sido relatados por diversos pesquisadores (Amsel, 1983; Eschenbach et al., 1988; HAY et al., 1994; Hillier et al., 1995; McGregor et al, 2000).

O diagnóstico da vaginose bacteriana tem passado por evolução ao longo do tempo. Originalmente feito por exclusão, Amsel formalizou e validou os sinais clínicos que foram descritos por Gardner e Dukes. Os critérios de Amsel permitem o diagnóstico de B.V. por 4 aspectos: (1) corrimento branco homogêneo; (2) pH vaginal > 4,5; (3) Teste das aminas com $\mathrm{KOH} 10 \%$; (4) presença de células alvo. A presença de 3 das 4 características estabelece o diagnóstico (Amsel, 1983; Scwebke, 1997).

Entretanto, os critérios clínicos de Amsel podem apresentar algumas desvantagens na caracterização da vaginose bacteriana. $O$ corrimento vaginal é o indicador mais subjetivo de V.B.. A diferença entre a quantidade de fluido vaginal nesta afeção e o fluido normal pode ser bastante sútil, além disso, este corrimento dito homogêneo pode se apresentar espumoso em algumas pacientes. Falsas elevações do $\mathrm{Ph}$ também podem ocorrer na presença de sangue menstrual, muco cervical ou sêmen. O odor das aminas, apesar de ser um critério específico é pouco sensivel. Dos critérios clínicos, a presença de células alvo é a característica mais específica e sensivel de vaginose bacteriana (Amsel et al., 1983; Eschenbach et al., 1988; Thomason et al., 1990; McGregor et al., 2000).

Inicialmente a caracterização de vaginose bacteriana era baseada apenas na presença de células alvo. Posteriormente, Nugent normatizou um método através da coloração de Gram, cuja avaliação passou a ser realizada com base em dados quantitativos de quatro morfotipos bacterianos, que determina um escore Valores de 7 a 10 caracteriza vaginose bacteriana (Nugent et al., 1991).

Uma variedade de técnicas diagnósticas que incluem: identificação de células alvo, em combinação com elevação do $\mathrm{pH}$ vaginal; coloração de Gram de secreção vaginal; testes cromatográficos da secreção vaginal; cultura quantitativas e métodos moleculares, têm sido desenvolvida na tentativa de diminuir a subjetividade dos critérios clínicos (Spiegel et al., 1983; Nugent et al.,1991; Sheiness et al., 1992; McGregor et al., 2000).

Considerando que a coloração de Gram é um método bastante acessivel e prontamente disponivel no laboratório de microbiologia, o presente trabalho teve como objetivo comparar os critérios clínicos de Amsel ao gradiente de Nugent na caracterização de vaginose bacteriana em pacientes sintomáticas ou com sinais e de infecção cérvico-vaginal, bem como, correlacionar cararacterísticas do conteúdo vaginal e sintomas em pacientes com vaginose bacteriana.

\section{PACIENTES E MÉTODOS}

Foram analisadas amostras de conteúdo vaginal de 100 pacientes na menacme, atendidas no setor de Ginecologia e Obstetrícia do Ambulatório do Hospital de Clínicas, no período de setembro de 1999 a outubro de 2000. Os critérios de inclusão foram sinais e sintomas de infecção cérvico-vaginal como: aumento de exsudato vaginal, prurido, ardor, aspecto, cor, dispareunia, ectopia cervical.

Foram excluídas aquelas pacientes que tinham utilizado antibióticos nos 30 dias antecedente à coleta, realizado ducha vaginal no dia do exame, estavam menstruadas, ou que não estavam em abstinência sexual por pelo menos 24 horas.

Durante o exame clínico foram determinados os critérios de Amsel (Tabela 1), onde foi realizado uma minuciosa avaliação da genitália externa, observando o conteúdo vaginal no seu aspecto, cor e quantidade.

$\mathrm{O} \mathrm{pH}$ foi medido utilizando-se fitas ou papel de filtro contendo indicador de $\mathrm{pH}$. Para o teste das aminas coletou-se uma porção de conteúdo vaginal e colocou-se sobre uma lâmina de vidro 
adicionando-se $\mathrm{KOH} 10 \%$. Foi considerado teste positivo quando havia liberação de odor de peixe em estado de putrefação.

Após o exame clínico foi realizado a coleta do conteúdo vaginal do fundo de saco de Douglas para exame a fresco e bacterioscopia ao Gram

No exame a fresco, o swab contendo material vaginal foi colocado no frasco com solução fisiológica estéril $0,85 \%$ e depositado uma gota sobre uma lâmina de vidro para microscopia e coberto com lamínula. A preparação foi visualizada em microscópio de campo claro em objetiva de $40 \mathrm{X}$, observando a presença de tricomonas, leveduras e de células alvo.

Para a bacterioscopia ao Gram, foi corada a lâmina contendo o esfregaço vaginal e realizado a leitura microscópia com objetiva de imersão (100X). As estruturas visualizadas foram quantificadas de 1 a 4+ (Tabela 2), tendo sido avaliada a redução de lactobacilos e o predomínio de cocos bacilos Gram variável tipo Gardnerella vaginalis, bacilos curvos tipo Mobiluncus spp. e bacilos Gram negativo pequenos tipo Prevotella spp. e Porphyromonas spp.

Para cada morfotipo foi verificado o valor correspondente na tabela. O escore individual para os 4 morfotipos foram somados e um escore total foi dado para interpretação: negativo para vaginose bacteriana (0-3), vaginose indeterminada (4-6) e vaginose bacteriana $(7-10)$

Tabela 1 - Critérios clínicos de Amsel para diagnóstico de vaginose bacteriana (V.B.)

\begin{tabular}{|c|c|c|}
\hline CRITÉRIO CLÍNICO & MÉTODO DO TESTE & DETECÇÃO EM B.V \\
\hline Corrimento & Visual & $\begin{array}{l}\text { Branco, Fino, } \\
\text { Homogêneo }\end{array}$ \\
\hline $\mathrm{pH}$ vaginal & Papel de $\mathrm{pH}$ & $>4,5$ \\
\hline Células alvo & Exame a fresco & $\begin{array}{c}\text { Presença obrigatória de células } \\
\text { escamosas do epitélio vaginal, } \\
\text { coberta por bactérias Gram } \\
\text { lábeis }\end{array}$ \\
\hline Teste de Whiff & $\mathrm{KOH} 10 \%$ & $\begin{array}{c}\text { Presença de odor de "peixe" } \\
\text { (aminas) }\end{array}$ \\
\hline
\end{tabular}

Necessário 3 critérios positivos de amsel para ser considerado vaginose bacteriana.

Tabela 2 - Critérios laboratoriais de Nugent: Avaliação da flora vaginal pela coloração de Gram.

\begin{tabular}{ccc}
\hline Morfotipos ao Gram & m.ol campo 1000x & Score \\
\hline Lactobacillus & Superior a 30 & 0 \\
& De 5 a 30 & 1 \\
& De 1 a 4 & 2 \\
Mobiluncus & Inferior a 1 & 3 \\
& Ausência & 4 \\
Superior a 5 & 2 \\
Gardnerella vaginalis & Inferior a 1 até 4 & 1 \\
Ou & Ausência & 0 \\
Bacteroides & Superior a 30 & 4 \\
& De 5 a 30 & 3 \\
& De 1 a 4 & 2 \\
\hline
\end{tabular}

Interpretação:

Score de 0 a 3 : secreções vaginais normais.

Score de 4 a 6 : vaginose indeterminada.

Score superior ou igual a 7 : vaginose bacteriana 


\section{RESULTADOS}

A etiologia de vaginose bacteriana foi definida em $34 \%$ das pacientes, com sinais e sintomas de infecção cervico-vaginal, analisadas neste estudo. A Tabela 3 mostra a frequêencia dos agentes infecciosos isolados.

A incidência de V.B. na população estudada foi de $34 \%$ usando os critérios laboratoriais e $14 \%$ utilizando os critérios clinicos. Quando o gradiente de Nugent foi usado como padrão ouro para diagnóstico, Amsel obteve uma sensibilidade de $41,2 \%$ e especificidade de 100\%. Quando Amsel foi utilizado como padrão ouro o gradiente de Nugent, obteve-se uma sensibilidade de $100 \%$ e especificidade de $75.9 \%$. Uma comparação entre os métodos é mostrada na Tabela 4. Não foi verificado concordância significativa entre os dois critérios utilizados para detectar V.B.(Kappa=0,47).

Tabela 3 - Freqüência de agentes etiológicos definidos pelo exame a fresco e coloração de Gram de 100 pacientes com indicação clínica ou sinais e sintomas de infecção cérvico-vaginal.

\begin{tabular}{lc}
\hline Vaginose bacteriana & $27 \%$ \\
\hline Candida sp & $11 \%$ \\
Vaginose bacteriana + Candida sp & $7 \%$ \\
Trichomonas sp & $1 \%$ \\
Outros & $54 \%$ \\
\hline
\end{tabular}

Tabela 4 - Comparação dos critérios de Amsel e gradiente de Nugent na caracterização de vaginose bacteriana, em 100 amostras de conteúdo vaginal.

\begin{tabular}{lccl}
\hline & Gradiente de & Nugent & \\
\hline Critérios de Amsel & Positivo & Negativo & Intermediário
\end{tabular}

Positivo

$14(\%)$

Negativo

$20(\%)$

$34(\%)$
$0(\%)$

$63(\%)$

$63(\%)$
$0(\%)$

$3(\%)$

$3(\%)$
Analisando os sinais clínicos, verificou-se que tanto nas pacientes com $V . B$. quanto naquelas sem V.B .o corrimento branco foi o mais freqüentemente observado, $72 \%$ e $75 \%$, respectivamente (Gráfico 1). Entre as pacientes com diagnóstico de vaginose, o aspecto homogêneo foi o mais freqüente $(49 \%)$, enquanto entre aquelas onde vaginose não foi observada, o aspecto mais comum foi o pastoso $44 \%$ (Gráfico 2).

Em ambos os grupos analisados a quantidade do conteúdo vaginal foi de discreta a moderada na maioria dos casos com $65 \%$ e $71 \%$, respectivamente (Gráfico 3). O Gráfico 4 apresenta os sintomas relatados pelas pacientes. Verificouse que em pacientes com V.B. o prurido não é uma caracteristica marcante, já que em $57 \%$ não foi referido. Ardor e disúria não estavam presentes em $63 \%$ e $80 \%$ das pacientes com vaginose bacteriana.

Alterações de $\mathrm{pH}$ vaginal foram observados em $81 \%$ das pacientes com V.B., significativamente maior que nas pacientes sem V.B. $19 \%$, como mostra o Gráfico 5 .

O teste das aminas foi positivo em $86 \%$ dos casos, sendo altamente preditivo no diagnostico das vaginoses bacterianas (Gráfico 6).

A associação com o número de leucócitos foi de discreta a moderada tanto nas pacientes que apresentaram somente vaginose bacteriana quanto aquelas associadas a Candida sp., respectivamente $86 \%$ e $75 \%$, como mostra o Gráfico 7 . 


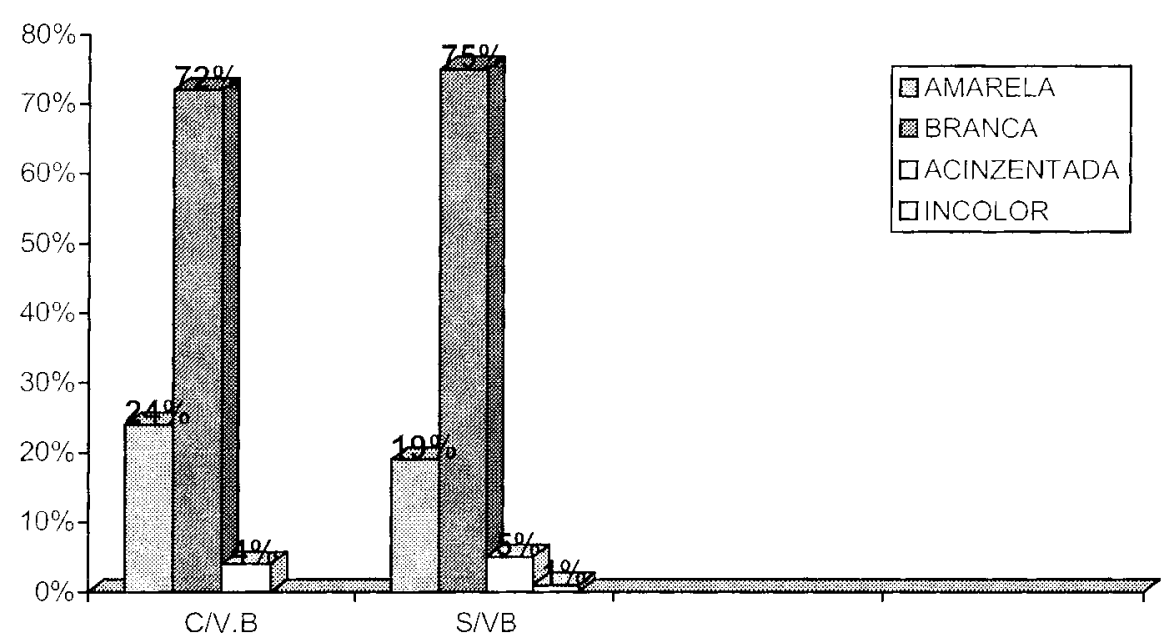

Gráfico 1 - Cor do conteúdo vaginal, em 100 pacientes com sinais e sintomas ou indicação clínica de infecção cérvico-vaginal.

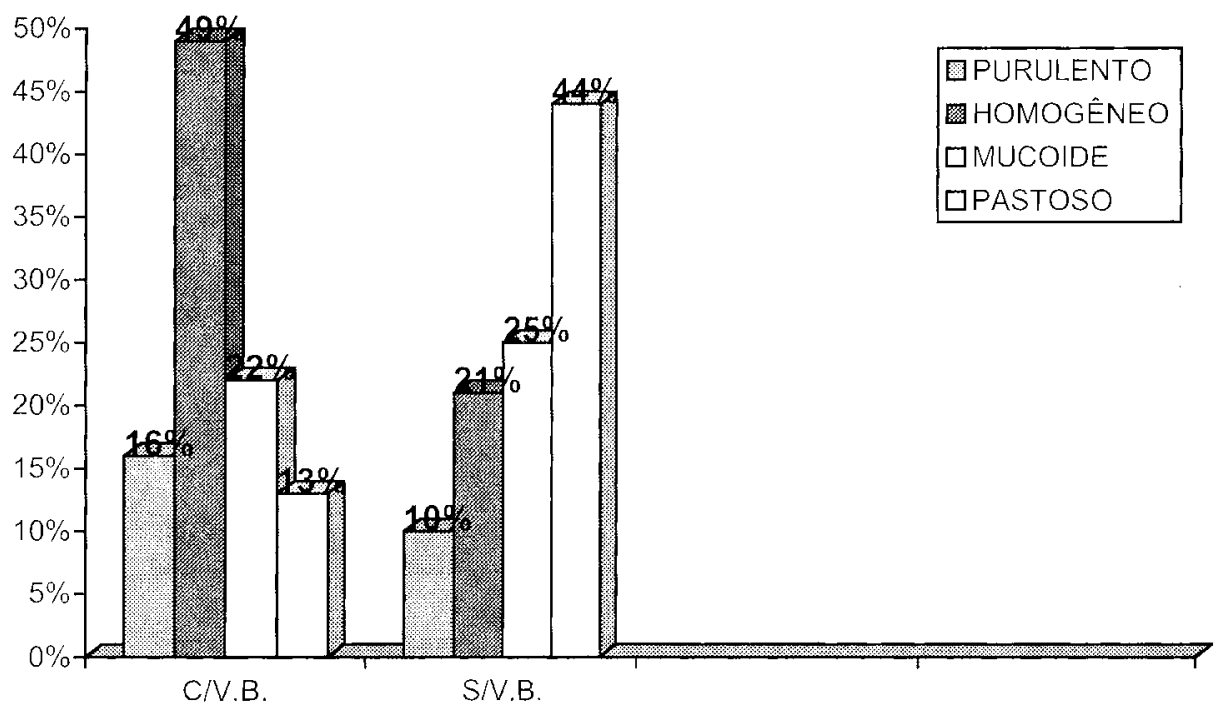

Gráfico 2 - Aspecto do conteúdo vaginal, em 100 pacientes com sinais e sintomas ou indicação clínica de infecçâo cérvico-vaginal.

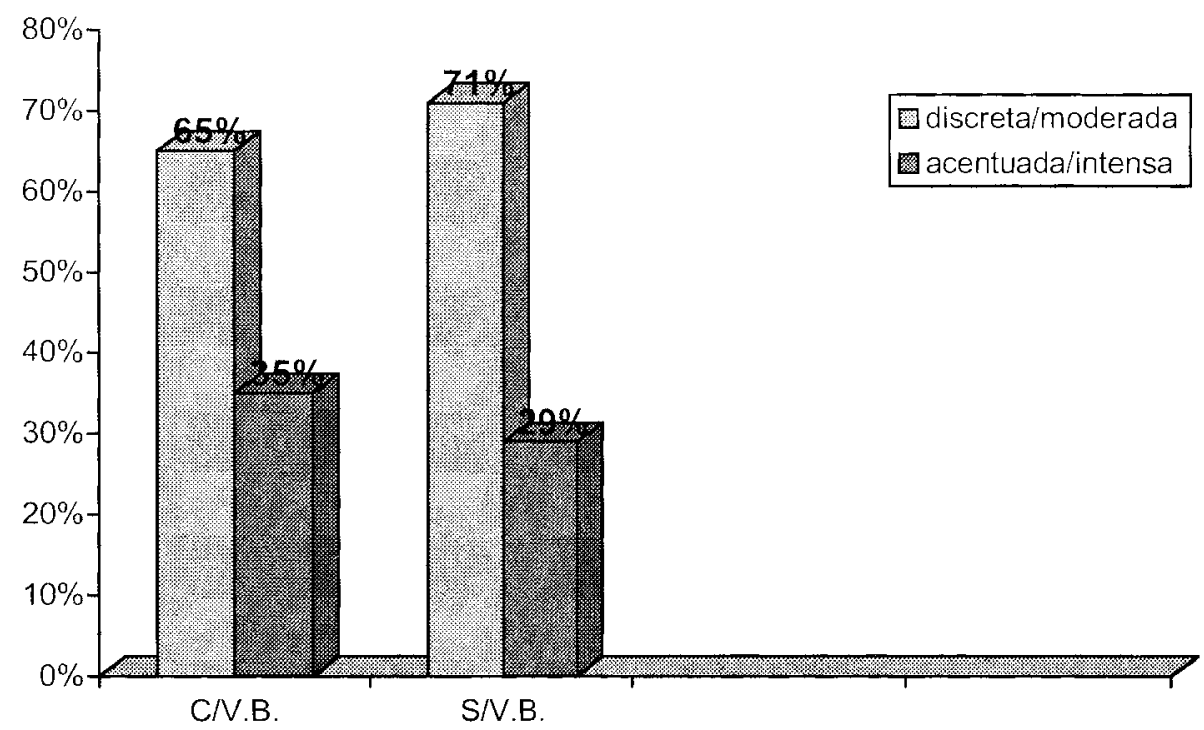

Gráfico 3 - Quantidade do conteúdo vaginal, em 100 pacientes com sinais e sintomas ou indicação clínica de infecção cérvico-vaginal. 


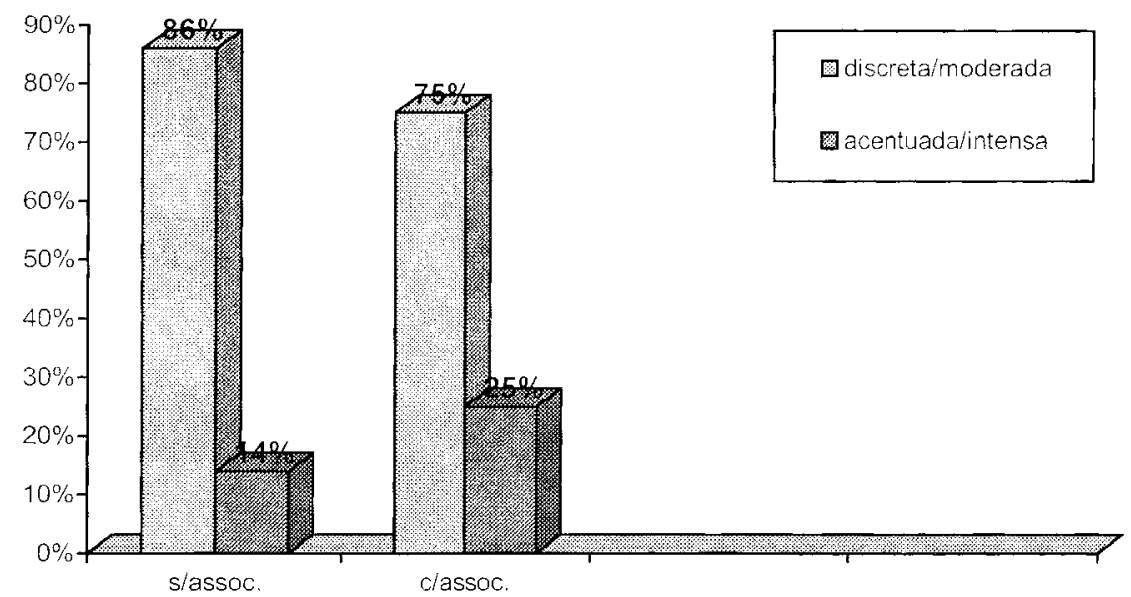

Gráfico 7 - Associação do $n^{\circ}$ de leucócitos do conteúdo vaginal com Candida albicans, em 34 amostras de vaginose bacteriana

\section{DISCUSSÃO}

Vaginose bacteriana tem sido relatada como a causa mais comum de corrimento vaginal (Hillier, 1993; Eschenbach, 1993; Scwebke, 1997).As descobertas de Gardner e Dukes, em em 1955, foram importantes na definição clínica da síndrome de V.B.. Entretanto, as técnicas de epidemiologia clinica utilizadas para separar mulheres com vaginose de mulheres normais, não foram amplamente aceitas, na época, pela maioria dos pesquisadores. A deficiência na definição de vaginose bacteriana, conduzia a uma situação em que paciente com queixa de aumento de corrimento vaginal poderiam ser diagnosticadas como vaginose bacteriana, por outro lado, o corrimento anormal poderia ter outras razões, como cervicite ou vaginite. A deficiência na na identificação clara de pacientes com V.B., contribuiu gravemente para os equívocos dos resultados microbiológicos. O conflito final desta época de ambigüidade foi a demonstração de $G$. vaginalis como organismo causador da vaginose bacteriana. Mais tarde, foi reconhecido que outros microrganismos anaeróbios estavam envolvidos na síndrome de V.B. (Eschenbach, 1993 ). Entretanto, $40 \%$ a $50 \%$ das mulheres sem evidência clínica de vaginite ou cervicite são Portadores de $G$. vaginalis. (Amsel, 1983).

Critérios clínicos têm sido amplamente utilizados para diagnosticar vaginose bacteriana. $O$ corrimento é descrito como de cor branca, fino e homogêneo; $\mathrm{pH}>4,5$; teste positivo para aminas e presença de células alvo (Amsel, 1983; Sobel, 1999; McGregor, 2000). Microbiologicamente, a síndrome de V.B. é definida pela mudança na microbiota vaginal. Há uma mudança da flora predominante de lactobacilos para uma flora mista, em que ocorre um grande aumento do número de bactérias, constituidos principalmente por anaeróbios e anaeróbios facultativos (Gardnerella, Mycoplasmas, Prevotella, Porphyromonas, Mobiluncus) e diminuição do número de lactobacilos, especialmente aqueles que produzem peróxido de hidrogênio. Esta mudança na flora pode ser demonstrada pela coloração de Gram e caracterizada como V.B. pelo método de Nugent (Schwebke, 1999). Hillier (1993) relata que o diagnóstico laboratoral é desejável quando o clínico tem situações ambíguas, por ser o teste laboratorial mais facilmente padronizado do que os subjetivos critérios clínicos.

Segundo Schwebke ( 1997), vaginose bacteriana ocorre em 20 a $25 \%$ da população geral e acima de $50 \%$ em mulheres atendidas em clínicas de D.S.T. Priestley et al. (1997), encontraram em seus estudos que $38 \%$ das mulheres sadias tinham V.B. intermitente. Considerando que este estudo foi conduzido em pacientes com indicação clínica, o indice de $34 \%$ de vaginose bacteriana encontrado, confirma os dados supostos por diversos autores, de que em paises em desenvolvimento a incidência desta afeção é bastante próxima, à da população dos paises desenvolvidos (Raddi et al., 1993).

$\mathrm{Na}$ utilização dos métodos clínicos, Khon et al. (1989), relatam uma prevalência de $21 \%$ de V.B., em mulheres grávidas, do mesmo modo, que Newman et al. (1998), encontraram uma incidência de $26 \%$. Entretanto, neste estudo, a incidência de vaginose bacteriana encontrada foi de apenas $14 \%$. Por outro lado, utilizando os métodos laboratorias, o indice de $34 \%$ de V.B. verificado nesta pesquisa, concorda com dados obtidos por Newman et al. (1998) de $30 \%$, discordando de Krohn et al. ( 1989) que encontrou $12 \%$.

Schwebke (1997), comparou os critérios de Amsel e Nugent e demonstrou para o gradiente de 
Nugent uma sensibilidade de $89 \%$ e especificidade de $83 \%$. Ao considerar a coloração de Gram como padrão ouro, Newman et al. (1998), encontraram para os critérios clínicos sensibilidade de $66,6 \%$ e especificidade de 90,6\%. Tam et al. (1998), obtiveram uma sensibilidade para os métodos clínicos de $46 \%$ e $91 \%$ para os critérios laboratoriais. Concordando com estes autores, foi encontrado neste trabalho que a sensibilidade do gradiente de Nugent demonstou-se maior (100\%) na caracterização de V.B. do que os critérios de Amsel $(41,2 \%)$. Enquanto a especificidade para os critérios clínicos foi de $100 \%$, contra $75,9 \%$ para os critérios laboratoriais.

O corrimento vaginal na V.B. tem sido referido por diversos autores como de cor branca, fino e homogêneo (Sobel, 1999; Spiegel, 1999; McGregor et al., 2000). Os dados encontrados neste estudo estão de acordo com os autores citados, já que estes foram, também, os mais freqüentes nas mulheres com V.B..

Eritema e inflamação freqüentemente estão ausente na V.B. e quando presentes podem ser causadas por outros agentes relacionados a vaginites e cervicites (Ryan et al.,1998; Sobel, 1999). A quantidade de leucócitos verificada neste estudo, quando presente, foi de discreta a moderada.

Ryan et al. (1998), relata que corrimento vaginal anormal indicativo de V.B., pode ser definido pelo aumento de quantidade de fluido e odor anormal. Entretanto, nesta pesquisa, não foi verificado aumento significativo na quantidade de fluido vaginal. Este fato, pode ser atribuido à subjetividade do observador.

Prurido, ardor e disúria não foram sintomas clínicos predominantes no grupo de pacientes analisados. De acordo com diversos autores, disúria e prurido vulvar têm sido mais relacionados com Candida albicanse Trichomonas vaginalis (Ryan et al., 1998; Sobel, 1999; McGregor et al., 2000). A freqüência de pacientes estudados que apresentaram estes sintomas, pode ser explicada pela associação com Candida albicans observada em cerca de $20 \%$ das amostras identificadas como V.B.

Uma das caracteristicas mais comumente relatadas nas mulheres com vaginose bacterina é a presença do odor de peixe ou odor das aminas. A produção das aminas é devido à combinação das bactérias anaeróbias associadas com V.B. Porém, este também é um critério subjetivo, que depende da habilidade, de pessoa para pessoa, para reconhecer o odor associado com V.B.. Chen et al.(1982), detectou este composto em $87 \%$ das mulheres com V.B., comparado com $14 \%$ daquelas sem vaginose. Da mesma forma, neste estudo, o teste das aminas foi positivo em $86 \%$ e $14 \%$ das mulheres com ou sem V.B., respectivamente.

Thinkhamrop et al. (1999), relata que a sensibilidade do teste do $\mathrm{pH}$ vaginal para qualquer tipo de vaginites é de aproximadamente $50 \%$, a sensibilidade aumenta para $73 \%$ quando aplicada somente para vaginose bacteriana. Vários fatores podem aumentar o $\mathrm{pH}$ vaginal. como relações sexuais, tratamento com antibiótico, reações inflamatórias e presença de microrganismos. Neste estudo, verificou-se que $81 \%$ das V.B. apresentaram o $\mathrm{pH}$ vaginal aumentado. A mudança do tipo de flora na vaginose bacteriana é precedido pelo aumento do $\mathrm{pH}$ vaginal, sugestionando que o seu aumento pode ser a causa maior do aparecimento desta condição.

Em virtude da subjetividade das variáveis clínicas utilizadas para caracterização de V.B., os critérios de Amsel apresentaram-se menos vantajosos em comparação ao gradiente de Nugent, nesta pesquisa. Considerando que a coloração de Gram é um método rápido, de baixo custo, altamente reprodutivel e utilizado em muitos laboratórios, sugere-se que o gradiente de Nugent possa ser considerado "padrão ouro" para o diagnóstico de vaginose bacteriana. 
VESPERO, E. C.; AZEVEDO, E. M. M.; PELISSON, M.; PERUGINI, M. R. E. Correlation between clinical criteria and laboratory criteria as diagnostic for bacterial vaginosis. Semina: Ci. Biol. Saúde, Londrina, $v$. 20/21, n. 2, p. 57-66, jun. 1999/2000.

\begin{abstract}
Bacterial vaginosis may be defined either by clinical or microbiological variables. Amsel's criteria allow for the diagnosis of bacterial vaginosis when three out of the following four criteria are detected.1) Vaginal $\mathrm{pH}>$ 4.5: 2): Positive amine test with $\mathrm{KOH} \mathrm{10 \% :} \mathrm{3);} \mathrm{Presence} \mathrm{of} \mathrm{clue} \mathrm{cells;} \mathrm{4)} \mathrm{Presence} \mathrm{of} \mathrm{a} \mathrm{white}$ thin and homogeneous vaginal discharge. This work's objective was to compare Amsel's criteria efficiency against Nugent's gradient on bacterial vaginosis diagnosis. Evaluation was performed on 100 samples of patients with signs and clinical symptoms of vaginal infection between September of 1999 and October of 2000 at the gynecology and obstetrics unit of the "Hospital de Clinicas". The patients were submitted to gynecological examinations in order to verify the mucous appearance and vaginal fluids. Samples were collected to measure the vaginal $\mathrm{pH}$, perform the amine test, wet mount and stain Gram. The Nugent's gradient was determined and compared to the Amsel's criteria for the characterization of the bacterial vaginosis. The incidence of bacterial vaginosis among the studied subjects was $34 \%$ for the laboratorial criteria and $14 \%$ for the clinical criteria. There was no meaningful concordance (Kappa $=0,47$ ) between Amsel's criteria and the Nugent gradient. This conclusion leads to a necessity for a discussion about the medical gynecological routine, which characterizes bacterial vaginosis only through clinical signs.
\end{abstract}

KEY WORDS: Bacterial vaginosis; clinical criteria; laboratory criteria.

\title{
REFERÊNCIAS BIBLIOGRÁFICAS
}

AMSEL,R. Nonspecific vaginitis: diagnostic criteria and microbial and epidemiologic associations. American Journal Medicine, v. 74, p. 14-18, 1983.

BARNES,R.C. Laboratory diagnosis of human Chlamidial infections. Clinical Microbiology.v. 2, n. 2, p. 119-136, 1989.

$\mathrm{CA \cup CI}, S$. et al. Immunoglobulin $A$ response against Gardnerella vaginalis hemolysin and sialidase activity in bacterial vaginosis. American Journal of Obstetrics and Gynecology, v.178, n.3, p.511-515, Mar. 1998.

CHEN, K.C.S et al. Biochemical diagnosis of vaginitis: determination of diamine in vaginal fluid. Journal infectious Disease, v. 145, p.337-345, 1982.

ESCHENBACH, D.A. Diagnosis and clinical manifestations of bacterial vaginosis. American Journal of Obstetrics and Gynecology, v.158. p. 819, 1988.

ESCHENBACH, D. History and review of bacterial vaginosis. American Journal of Obstetrics and Gynecology, v.169, n. 2s, p.441-445, Aug. 1993.

FONSECA, A.M. et al. Mecanismos de defesa do aparelho genital feminino in Monteneoe \& Valente. Infectologia em Ginecologia e Obstetricia. São Paulo: Atheneu, 1997.

HAAS,P. et al. Doenças sexualmente transmissiveis associada a mulheres portadoras do virus HIV. Revista Newslab, v..36, p. 162-168, 1999.

HAY, P.E.et al. Abnormal bacterial colonization of de genital tract and subsequent preterm delivery and late miscarriage. Britanish Medical Journal, n. 308, p. 295-298, 1994.

HIL., G.B.; LIVENGOOD, C.H. Bacterial vaginosis - associated microflora and effects of topical intravaginal clindamycin. American Journal of Obstetrics and Gynecology, v.171, n. 5 , p. 1198-1204, 1994.

HILLIER, S.L Diagnostic microbiology of bacterial vaginosis. American Joumal of Obstetrics and Gynecology, v. 169, n. 2s, p. 455-459, Aug. 1993.

KROHN, M.; HILLIER, S.L.; ESCHENBACH, D. Comparasion of methods for dianosing bacterial vaginosis among pregnant women. Journal Clinical Microbiology, v.27, p. 1266-1271, 1989 .

LUCENA. AL.M. ; BARBOSA, R.C.C. Incidência de Trichomonas vaginalis, Gardnerella vaginalis e fungos, em secreçōes vaginais de mulheres grávidas. Revista Newslab. v. 35 p.208-214, 1999.

MCGREGOR, J.; JAMES, M.D.; FRENCH , J.I. Bacterial vaginosis in pregnancy. Obstetrical and Gynecology Survey, $v .55$, n. 5, p. 1-19, May 2000.

MACSEEN K.F.; RIDGWAY, G.L. The laboratory investigation of vaginal discharge. Journal of Clinical Pathology, v. 51, n. 8, p. $565-567$, Aug. 1998

NEWMAN, M. et al. Bacterial vaginosis in an inner -city obstetrical population: evulation of a new diagnostic test versus clinical and grain-stain criteria. American Journa of Obstetrics and Gynecology. v. 178, n. 1s, p.211s, Jan. 1998.

NUGENT R.P.; KROHN ,M.; HILLIER, S.L. Reliability of diagnosing bacterial vaginosisis improved by a standardized method of Gram stain interpretation. Journal Clinical Microbiology, v. 29, p. $297-301,1991$.

PRIESTLEY, C.J.F. What is normal vaginalflora?. Genitourinary Medicine, v. 73, n. 1, p. 23-28, Feb. 1997.

RADDI, M.S.G. Etiologia das infecções cérvico - vaginais em pacientes com indicação clinica. Revista Brasileira de Análises Clinicas, v. 25, n. 1, p. 17-22, 1993.

RYAN, C. et al. Risks assessment, symptoms, and signs as predictors of vulvovaginal and cervical infections in na urban US STD clinic: implications for use of STD algorithms. Sexually Transmittesd Infections, v. 74, n. 1s, p. 59s-76s, June 1998.

SCHWEBKE, J.R. Bacterial vaginosis-more questions than answers. Genitourinary Medicine , v. 73 , n. 5 , p. 333336, Oct. 1997.

SHEINESS ,D.; DIX, K.; WATANABE, S. et al. High levels of Gardnerella vaginalis detected with an oligonucleotide probe combined with elevated $\mathrm{pH}$ as a diagnostic indicator 
of bacterial vaginosis. Journal Clinical Microbiology, v. $30 ;$ p. 642-648, 1992

SOBEL, J.D. Current Concepts:Vaginitis. The New England Joumal of Medicine, v. 337, п. 26, p. 1896-1903, Dec. 1997.

SOBEL, J.D. Vulvovaginites in healthy women. Comprehensive Therapy. v. 25, n.6, p. 335-346, June, 1999.

SPIEGEL, C.; AMSEL. R.; HOLMES. K.K. Diagnosis of bacterial vaginosis by direct Gram stain of vaginal fluid. Journal Clinical Microbiology, v. 18, p. 170-177, 1983.

SPIEGEL, C.A. Bacterial vaginosis. Clinical Microbiology Review, v. 4, p. 484-502, 1991

SPIEGEL, C. Bacterial Vaginosis:charges in laboratory practice. Clinical Microbiology Newsletter, v.21, n. 5, p. 33-37, Mar. 1999.
TAM, M.T.; YUNGBLUTH, M.; MYLES, T. Gram stain method shows better sensitivity than clinical criteria for detection of bacterial vaginosis in surveiliance of pregnant. lowincome women in a clinical setting. Infectious Diseases in Obstretics \& Gynecology, v. 6, n. 5. p. 204-208, 1998

THOMASON, J.L.; GELBART, S.M.; ANDERSON, R.J. et al. Statistical evaluation of diagnostic criteria for bacterial vaginosis. American Journal of Obstetrics and Gynecology. v. 162, p. $155-160,1990$.

THOMASON,J.L.;GELBART,S.M.,SCAGLIONE,N.J. Bacterial vaginosis:current review wit indications for asymotimatic therapy. Amercian Journal of Obstetrics and Gynecologyl, v. 165, p.1210-1217, 1991.

THINKHAMROP, P.L. et al. Vaginal fluid pH as a screening test for vaginitis. International Journal of Gynecology \& Obstetrics, v. 66, n. 2, p.143-148, mar. 1999. 